\title{
Heat-Shock-Induced Glucose Transporter 4 in the Slow-Twitch Muscle of Rats
}

\author{
P.-F. WU ${ }^{1}$, S.-C. LUO ${ }^{1}$, L.-C. CHANG ${ }^{2}$ \\ ${ }^{1}$ Department of Kinesiology, Health and Leisure Studies, National University of Kaohsiung, \\ Kaohsiung, Taiwan, ${ }^{2}$ Department of Occupational Therapy, I-Shou University, Kaohsiung, Taiwan
}

Received February 24, 2014

Accepted November 4, 2014

On-line December 3, 2014

\begin{abstract}
Summary
In this study, lipoic acid and heat shock treatments were applied to $\mathrm{C}_{2} \mathrm{C}_{12}$ myotubes and Sprague-Dawley rats to investigate changes in the heat shock protein 70 (HSP70) and glucose transporter 4 (GLUT4) in 4 different skeletal muscle groups. The results of western blotting indicated that treatment of lipoic acid for $24 \mathrm{~h}$, heat-shock and combined lipoic acid and heat-shock which all increased the level of HSP70 substantially in $C_{2} C_{12}$ myotubes. However, either lipoic acid or heat-shock did not increase the level of GLUT4 in $\mathrm{C}_{2} \mathrm{C}_{12}$ myotubes. In an in vitro migration assay, lipoic acid increased wound migration only when it was applied for $3 \mathrm{~h}$. Moreover, our in vivo results revealed that lipoic acid did not increase HSP70 and GLUT4 in all 4 different skeletal muscles. Furthermore, heat-shock increased HSP70 in all 4 different muscle groups, and heat-shock treatment alone increased the GLUT4 in the soleus muscle only, suggesting that the GLUT4 increased by heat-shock was slow-twitch muscle specific. Collectively, our results indicated that heat-shock is critical factor that modulates GLUT4 and HSP70 in the skeletal muscle of rats.
\end{abstract}

\section{Key words}

Lipoic acid • Skeletal muscle groups - Heat-shock • Wound migration • Heat shock protein 70 (HSP70) • Glucose transporter 4 (GLUT4)

\section{Corresponding author}

P.-F. Wu, Department of Kinesiology, Health and Leisure Studies, National University of Kaohsiung, 81148 Kaohsiung, Taiwan. Fax: +886-7-5919264. E-mail: anniepf@nuk.edu.tw

\section{Introduction}

In mammals, skeletal muscle is a mosaic of discrete types of muscle fiber with various structural properties and functional capabilities. A complex and heterogeneous mixture of skeletal muscle contractile proteins of distinct isoforms generates various muscle fiber types, each with distinct histochemical and functional characteristics (Liu and Steinacker 2001). Based on the classification of myosin heavy chain isoforms, human skeletal muscles are divided into 2 major fiber types, Type I and Type II (IIa and IIx), whereas rodent skeletal muscles are classified into Types I, IIa, IIb, and IIx. Type I corresponds to slow-twitch muscles (more aerobic) and Type II corresponds to fast-twitch muscles (less aerobic). Skeletal muscle is a highly adaptive tissue of which the responses to alterations in functional demand can include changes in the morphological, phenotypic, metabolic, and mechanical properties of muscle fibers, thereby complicating studies on this tissue.

Most studies of lipoic acid have focused on its ability to scavenge reactive oxygen and nitrogen species, inhibit reactive oxygen generators, and regenerate other antioxidants (Bast and Haenen 1988). In addition, Zhang et al. (2011) demonstrated that lipoic acid increases glucose uptake in type 2 diabetes mellitus and exhibits antiobesity effects. Therefore, lipoic acid has long been used to clinically treat diabetic neuropathy (Shay et al. 2009). Lipoic acid not only can scavenge reactive oxygen and nitrogen species, inhibit reactive oxygen generators, and regenerate other antioxidants but also can be combined with coenzyme Q10 (Co Q10) to improve the 
energy metabolism and integrity of skeletal muscles (Wagner et al. 2012). Although Abadi et al. (2013) reported that combining lipoic acid with Co Q10 and vitamin $\mathrm{E}$ enhanced running performance in untrained female mice, the effects of lipoic acid on distinct skeletal muscles has rarely been studied. Furthermore, Leu et al. (2012) suggested that combining lipoic acid with epigallocatechin gallate accelerates cutaneous wound healing in mice. However, Yamazaki et al. (2014) demonstrated that lipoic acid suppresses migration and invasion in bladder cancer cells. The inconsistencies regarding the role of lipoic acid in cell migration and wound healing should be clarified.

A study showed that heat shock protein 70 (HSP70) is expressed at higher levels in slow-twitch muscles than in fast-twitch muscles and that HSP70 expression in muscles is fiber type specific (Locke et al. 1991). However, chronic induction of HSP70 expression in rat skeletal muscles may not always indicate the slowfiber phenotype (Tarricone et al. 2008). Thus, the relationship between HSP70 expression and muscle fiber types has not been elucidated completely. Moreover, because skeletal muscle is responsible for most insulinmediated glucose disposal in the body, the expression of HSP70 in distinct muscle fibers in response to exposure to lipoic acid or heat-shock can be clarified to provide crucial information for designing exercise programs. Glucose transporter 4 (GLUT4) is the main facilitative glucose carrier responsible for insulin-regulated glucose uptake in skeletal muscle (Scheepers et al. 2004). Stuart et al. (2010) reported that exercise increases GLUT4 in fast-twitch muscles, and Xiao et al. (2013) indicated that exercise increases GLUT4 in both fast-twitch and slowtwitch muscles. These findings motivated us to clarify the response of GLUT4 to lipoic acid or heat-shock in different muscles.

In this study, lipoic acid and heat-shock were applied to $\mathrm{C}_{2} \mathrm{C}_{12}$ myotubes and Sprague-Dawley (SD) rats for 21 days. The rats were then sacrificed and 4 whole different muscle groups, namely the extensor digitorum longus, diaphragm, gastrocnemius, and soleus, were collected. Our results indicated that heat-shock increased the slow-twitch-muscle-specific GLUT4 in SD rats.

\section{Methods}

\section{Preparation of $C_{2} C_{12}$ myotubes}

Portier et al. (1999) reported that $\mathrm{C}_{2} \mathrm{C}_{12}$ cells exhibited spontaneous contraction properties after they were differentiated into myotubes by using a low concentration of horse serum; the same concentration of horse serum was used in this study. $\mathrm{C}_{2} \mathrm{C}_{12}$ cells were derived from a mouse muscle cell line (BCRC 60083) and purchased from the Food Industry Research and Development Institute, Taiwan. The cells were cultured in Dulbecco's modified Eagle's medium (DMEM), which contained $25 \mathrm{mM}$ glucose, $2 \mathrm{mM}$ glutamine, and $10 \%$ fetal calf serum (Gibco-BRL), and were grown at $37^{\circ} \mathrm{C}$ in a humidified environment with $5 \% \mathrm{CO}_{2}$. To induce the formation of myotubes, the medium was replaced with DMEM containing $2 \%$ horse serum, $25 \mathrm{mM}$ glucose, and $2 \mathrm{mM}$ glutamine before the myoblasts reached 30-40\% confluence, and then the cultures were maintained for 3-5 days at $37{ }^{\circ} \mathrm{C}$ in a humidified environment with $5 \% \mathrm{CO}_{2}$.

\section{Treatment with lipoic acid and heat shock}

After the $\mathrm{C}_{2} \mathrm{C}_{12}$ myotubes reached $80-90 \%$ confluence, lipoic acid (final concentration, $0.5 \mathrm{mM}$; Sigma Chemical) was added to the culture medium and the cultures were incubated for 3 or $24 \mathrm{~h}$. For the $3 \mathrm{~h}$ treatment of lipoic acid, cells were incubated at $37{ }^{\circ} \mathrm{C}$ in a $5 \% \mathrm{CO}_{2}$ incubator for $21 \mathrm{~h}$, lipoic acid was added and incubation was continued for $3 \mathrm{~h}$, and the cells were harvested immediately. For the heat shock treatment, cells were incubated at $42{ }^{\circ} \mathrm{C}$ in a $5 \% \mathrm{CO}_{2}$ incubator for $3 \mathrm{~h}$ before they were harvested. Control cells were maintained for $24 \mathrm{~h}$ at $37^{\circ} \mathrm{C}$ in a humidified environment with $5 \% \mathrm{CO}_{2}$.

Sodium dodecyl sulfate polyacrylamide gel electrophoresis and western blotting

$\mathrm{C}_{2} \mathrm{C}_{12}$ myotubes or muscle tissues were lysed in a radioimmunoprecipitation assay buffer $(50 \mathrm{mM}$ Tris at pH 7.4, 150 mM NaCl, 2 mM EDTA, $1 \%$ Triton X-100, $1 \% \mathrm{NP}-40$, and $0.25 \%$ sodium deoxycholate) containing protease inhibitors (Complete, Boehringer Mannheim). The samples were maintained on ice for $5 \mathrm{~min}$ and then centrifuged at $10,000 \times g$ for $15 \mathrm{~min}$ to remove insoluble materials. The protein concentration of the supernatants was measured using a BCA kit (Pierce Biotechnology, Inc., USA). For each sample, $50 \mu \mathrm{g}$ of the protein lysate was separated on $10 \%$ or $15 \%$ polyacrylamide gels and then transferred to polyvinylidene difluoride membranes by using a semidry transfer apparatus (Bio-Rad). The membranes were blocked in $5 \%$ nonfat dry milk in the TBST buffer (25 mM Tris at $\mathrm{pH} 7.5,135 \mathrm{mM} \mathrm{NaCl}$, and $0.15 \%$ Tween-20) for $1 \mathrm{~h}$ and then incubated with antiactin (Santa Cruz Biotechnology, Inc.) for $1 \mathrm{~h}$, or with 
anti-HSP70 (Santa Cruz Biotechnology, Inc.) or antiGLUT4 (Thermo Fisher Scientific) for $2 \mathrm{~h}$. The blots were washed using TBST and then incubated for $50 \mathrm{~min}$ with secondary antibodies conjugated to horseradish peroxidase (Bio-Rad). The immunoreactive proteins were detected using an enhanced chemiluminescence detection system (Amersham Biosciences) according to the manufacturer's instructions.

\section{In vitro migration/wounding assay}

$\mathrm{C}_{2} \mathrm{C}_{12}$ myoblasts were seeded into 24-well plates and differentiated in a culture medium containing $25 \mathrm{mM}$ glucose. After $\mathrm{C}_{2} \mathrm{C}_{12}$ myotubes reached 70-80\% confluence, the cell monolayer was scratched using a fine needle and the cells were allowed to continue growing in a $5 \% \mathrm{CO}_{2}$ incubator for $24 \mathrm{~h}$; these cells constituted the control group. To create experimental groups, after the cells were scratched, lipoic acid at a final concentration of $0.5 \mathrm{mM}$ was added to the culture medium, and the cultures were incubated for 3 or $24 \mathrm{~h}$. For the experimental group treated for $3 \mathrm{~h}$, lipoic acid was added after wounding and removed after $3 \mathrm{~h}$ of treatment; the cells continued to incubate for $21 \mathrm{~h}$. The distances migrated by the cells were measured after $24 \mathrm{~h}$, and the percentage of wound closure was calculated using ImageJ Free Software, Version $1.47 \mathrm{~V}$ (NIH, Bethesda, Maryland, USA).

\section{Animals and experimental design}

All experiments were performed according to the guidelines provided by an experimental animal laboratory and were approved by the Animal Care and Use Committee of E-Da Hospital. For this study, 15 male SD rats initially weighing 180-200 g were purchased from BioLASCO Taiwan Co., Ltd. The rats were maintained on a 12-h light/dark (light-dark: 09:00-21:00) cycle at constant room temperature $\left(24 \pm 2{ }^{\circ} \mathrm{C}\right)$ and humidity $(60 \%)$ and provided food and tap water ad libitum throughout the experiments. The rats were randomly divided into 4 groups: (1) control ( $\mathrm{n}=3$; weight: $415 \pm 11 \mathrm{~g})$, (2) lipoic acid injection ( $\mathrm{n}=4$; weight: $420 \pm 18$ g), (3) heat shock ( $\mathrm{n}=4$; weight: $417 \pm 16 \mathrm{~g})$, and (4) combined lipoic acid injection and heat-shock treatment ( $\mathrm{n}=4$; weight: $410 \pm 18 \mathrm{~g}$ ). The rats in the control group were injected intraperitoneally with the maximal volume of dimethyl sulfoxide which was the solution used to prepare lipoic acid, daily for 21 days. The rats in the lipoic acid injection groups were injected intraperitoneally with lipoic acid ( $50 \mathrm{mg} / \mathrm{kg}$ body weight) daily for 21 days. Once per week, the rats in the heat- shock treatment groups were anesthetized by intraperitoneally injecting them with $10 \mathrm{mg} / \mathrm{kg}$ body weight of Zoletil ${ }^{\circledR}$ (Virbac S.A.) and then placed in a $42{ }^{\circ} \mathrm{C}$ circulation oven. The rats were removed from the oven $15 \mathrm{~min}$ after the rectal temperature had risen to $40{ }^{\circ} \mathrm{C}$. In the combined lipoic acid injection and heatshock treatment group, heat-shock treatment was performed $1 \mathrm{~h}$ after lipoic acid was injected. The treatments were administered for 3 weeks. The rats were sacrificed the day after the final treatment, and the extensor digitorum longus, diaphragm, gastrocnemius and soleus muscle groups were obtained.

\section{Densitometry and data analysis}

Blotting was performed at least in triplicate, and the blot was scanned and quantified using Carl Zeiss Axio Vision Rel. 4.6 software. The in vitro data obtained in this study are expressed as the mean \pm mean of the standard deviation (SEM) based on measurements conducted in triplicate. The in vivo data obtained in this study are expressed as the group mean \pm SEM based on measurements of each rat conducted in triplicate. Except in the migration/wounding assay, significant differences were determined by performing a one-way ANOVA by using MS Excel 2010 software. The means were compared with the control by conducting the Student's $t$ test by using Sigmaplot software, Version 10.0. A $P$ value $<0.05$ or $<0.01$ indicated statistical significance.

\section{Results}

Lipoic acid induces robust HSP70 expression in response to heat-shock

As shown in Figure 1, treatment with lipoic acid for $24 \mathrm{~h} \quad(P<0.01)$ or heat shock alone $(P<0.01)$ significantly increased the HSP70 in $\mathrm{C}_{2} \mathrm{C}_{12}$ myotubes. Moreover, both $3 \mathrm{~h}$ and $24 \mathrm{~h}$ combined lipoic acid and heat-shock treatment increased substantial HSP70 $(P<0.01)$. By contrast, neither lipoic acid treatment nor heat-shock treatment alone increased the level of GLUT4 (Fig. 2).

Short-term treatment with lipoic acid improves wound migration

Wound healing is impaired in animals experiencing long-term hyperglycemia (Tandara and Mustoe 2004). To determine how lipoic acid affects wounded tissues, we applied lipoic acid to scratched cells and examined the migration of cells into the wound after 3 

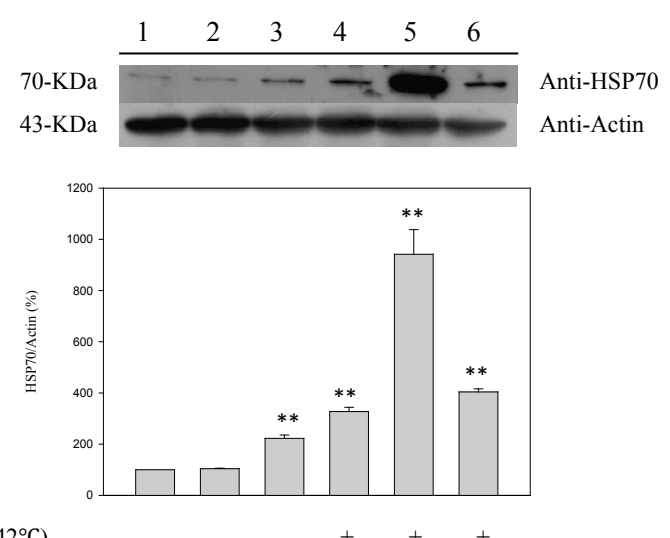

Heat-shock $\left(42^{\circ} \mathrm{C}\right)$

$0.5 \mathrm{mM}$ LA $3 \mathrm{~h}$

$0.5 \mathrm{mM}$ LA $24 \mathrm{~h}$

Fig. 1. Expression of $\mathrm{HSP70}$ in $\mathrm{C}_{2} \mathrm{C}_{12}$ myotubes. Lane 1 corresponds to $50 \mu \mathrm{g}$ of a protein lysate harvested from $\mathrm{C}_{2} \mathrm{C}_{12}$ myotubes. Lane 2 corresponds to lysates of $\mathrm{C}_{2} \mathrm{C}_{12}$ myotubes treated with $0.5 \mathrm{mM}$ lipoic acid (LA) for $3 \mathrm{~h}$. Lane 3 corresponds to lysates of $C_{2} C_{12}$ myotubes treated with $0.5 \mathrm{mM}$ lipoic acid for $24 \mathrm{~h}$. Lane 4 corresponds to lysates of $\mathrm{C}_{2} \mathrm{C}_{12}$ myotubes treated with heat shock for $3 \mathrm{~h}$. Lanes 5 and 6 correspond to lysates of $\mathrm{C}_{2} \mathrm{C}_{12}$ myotubes treated with heat-shock and $0.5 \mathrm{mM}$ lipoic acid for 3 and $24 \mathrm{~h}$, respectively. Data are presented as the mean \pm SEM of 3 measurements. ** $P<0.01$

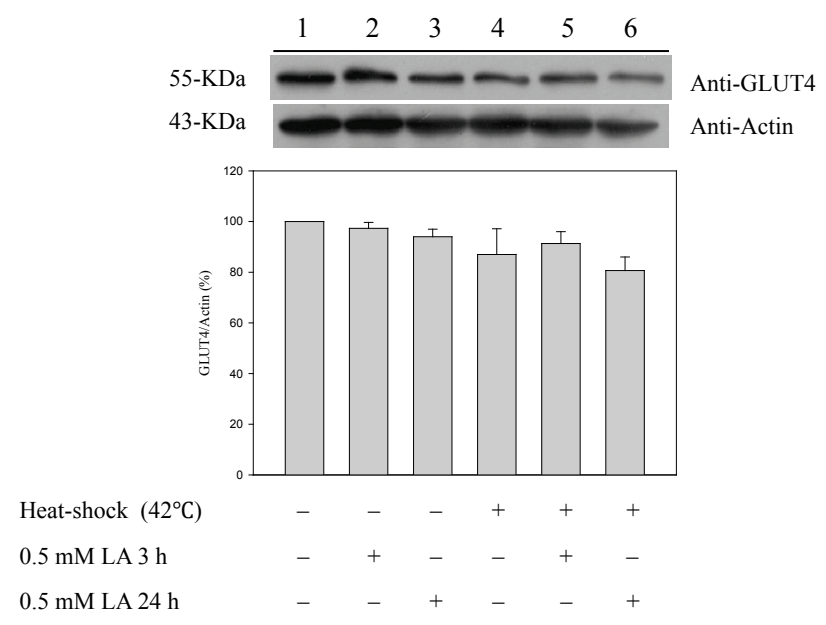

Fig. 2. Expression of GLUT4 in $\mathrm{C}_{2} \mathrm{C}_{12}$ myotubes. Lane 1 corresponds to $50 \mu \mathrm{g}$ of a protein lysate harvested from $\mathrm{C}_{2} \mathrm{C}_{12}$ myotubes. Lane 2 corresponds to lysates of $\mathrm{C}_{2} \mathrm{C}_{12}$ myotubes treated with $0.5 \mathrm{mM}$ lipoic acid (LA) for $3 \mathrm{~h}$. Lane 3 corresponds to lysates of $\mathrm{C}_{2} \mathrm{C}_{12}$ myotubes treated with $0.5 \mathrm{mM}$ lipoic acid for $24 \mathrm{~h}$. Lane 4 corresponds to lysates of $\mathrm{C}_{2} \mathrm{C}_{12}$ myotubes treated with heat-shock for $3 \mathrm{~h}$. Lanes 5 and 6 correspond to lysates of $\mathrm{C}_{2} \mathrm{C}_{12}$ myotubes treated with heat-shock and $0.5 \mathrm{mM}$ lipoic acid for 3 and $24 \mathrm{~h}$, respectively. Data are presented as the mean \pm SEM of 3 measurements. $* P<0.05$

and $24 \mathrm{~h}$ by performing microscopy. As shown in Figure 3, $\mathrm{C}_{2} \mathrm{C}_{12}$ myotubes migrated into the wound area, and wound closure after $3 \mathrm{~h}$ in the presence of lipoic acid was $50 \%$ greater than that in the absence of lipoic acid $(P<0.01)$. However, after $24 \mathrm{~h}$, wound closure when lipoic acid treatment was administered was $22 \%$ lower than that in

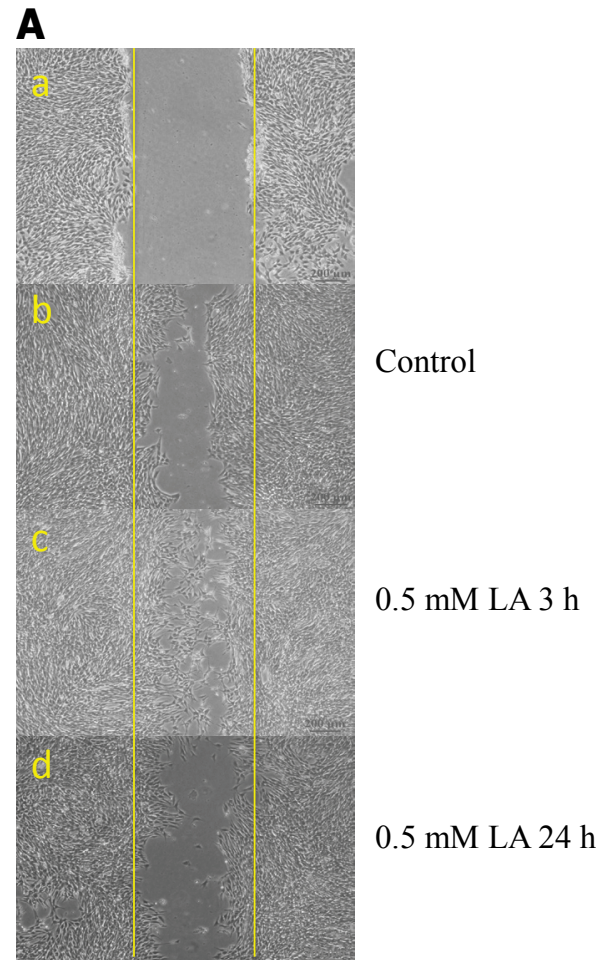

B

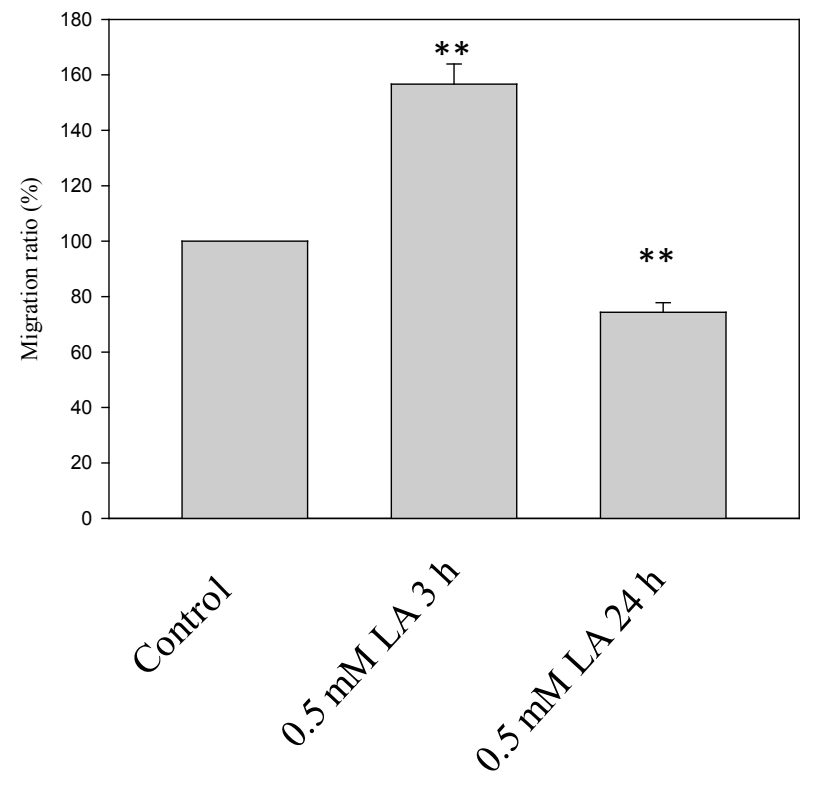

Fig. 3. Lipoic acid (LA) improves migration and wound closure in $\mathrm{C}_{2} \mathrm{C}_{12}$ myotubes. (A) A monolayer of $\mathrm{C}_{2} \mathrm{C}_{12}$ myotubes was scratched with a needle to create a wound (a). Wound closure was examined $24 \mathrm{~h}$ after wounding (b). In the $3 \mathrm{~h}$ treatment, lipoic acid was added after wounding and removed after $3 \mathrm{~h}$; the cells continued to incubate for $21 \mathrm{~h}$ (c). In the $24 \mathrm{~h}$ treatment, lipoic acid was added immediately after wounding (d). (B) The wound closure ratio was calculated using ImageJ software. Data are presented as the mean \pm SEM of 3 measurements. ** $P<0.01$

the absence of treatment $(P<0.01)$, indicating that longterm lipoic acid treatment reduces cell migration. 
A

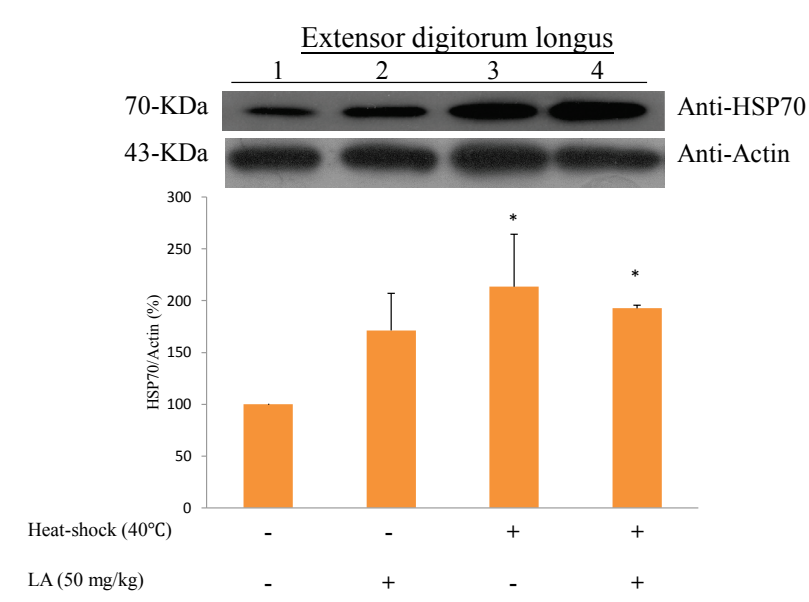

\section{C}

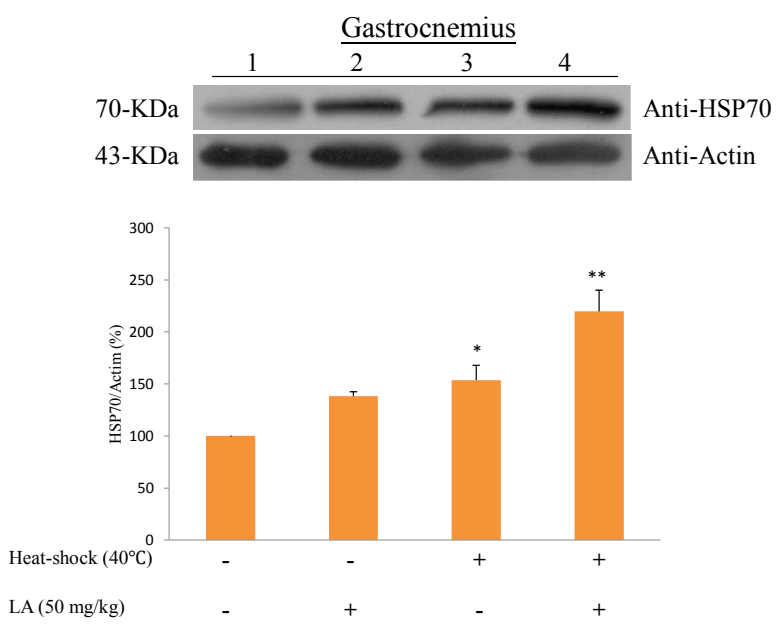

B

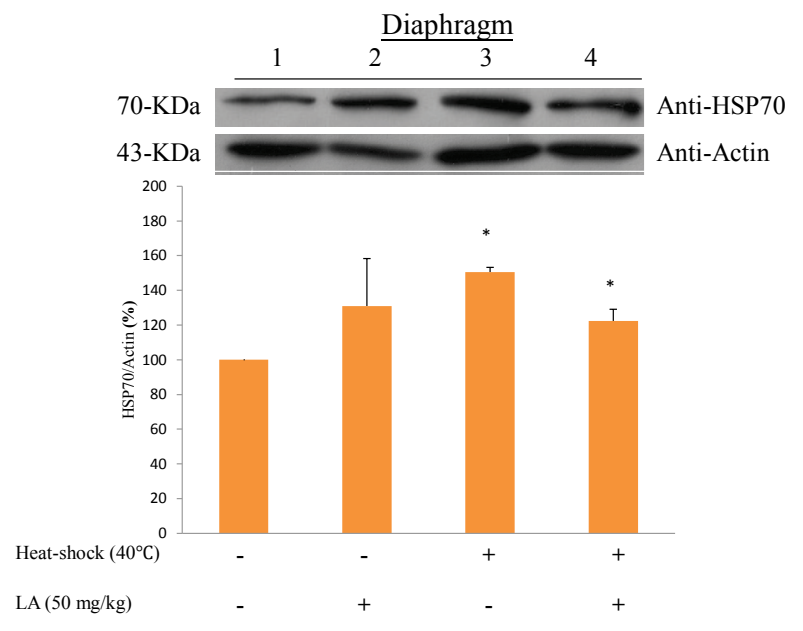

D

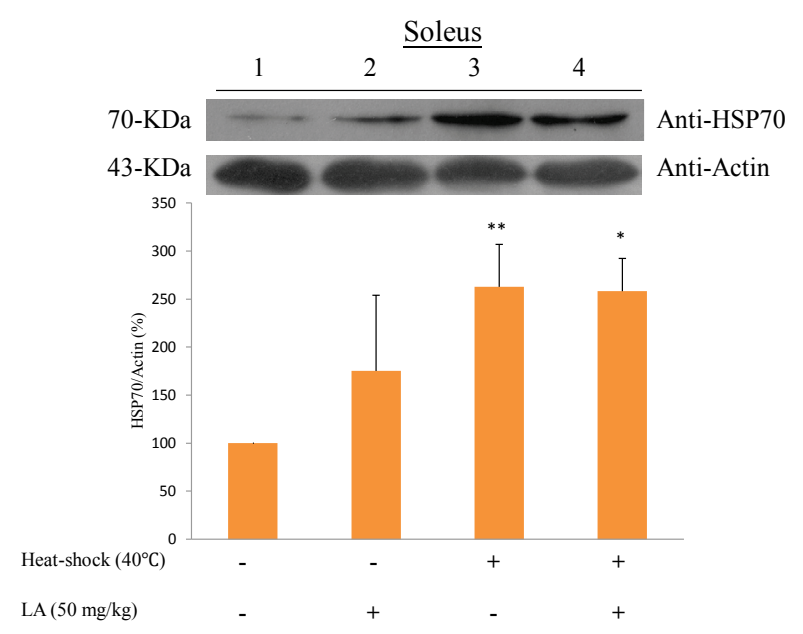

Fig. 4. Lipoic acid (LA) induced HSP70 expression in skeletal muscles subjected to heat shock. (A), (B), (C), and (D) correspond to $15 \mu \mathrm{g}$ of protein extracts prepared from extensor digitorum longus, diaphragm, gastrocnemius, and soleus muscles, respectively. Lane 1 corresponds to the protein extract of muscles from the control group $(n=3)$. Lane 2 corresponds to the protein extract of muscles from rats injected with lipoic acid alone $(n=4)$. Lane 3 corresponds to the protein extract of muscles from rats treated with heat-shock alone $(n=4)$. Lane 4 corresponds to the protein extract of muscles from rats treated with both lipoic acid and heat-shock $(n=4)$. Data are presented as group mean \pm SEM of 3 measurements of each rat. $* P<0.05, * * P<0.01$

Heat shock treatment induces muscle-specific glucose transporter 4 expression

Our in vivo experiments revealed that lipoic acid did not significantly increase the level of HSP70 in all 4 different skeletal muscles (Fig. 4A-D). Our results also indicated that heat-shock treatment significantly increased the HSP70 content in all 4 different muscles relative to the controls $(P<0.05$ at extensor digitorum longus, diaphragm and gastrocnemius; $P<0.01$ at soleus; Fig. 4A-D). Furthermore, lipoic acid failed to increase GLUT4 content in all 4 different skeletal muscles (Fig. 5A-D). Heat-shock treatment alone increased the GLUT4 content only in the soleus muscle $(P<0.01$;
Fig. 5D), and the GLUT4 content decreased in the extensor digitorum longus $(P<0.05$; Fig. 5A $)$ and diaphragm $(P<0.05$; Fig. 5B) muscles when combined lipoic acid and heat-shock treatment was applied. Collectively, these results suggested that the induction of HSP70 by heat-shock was not muscle specific and that heat-shock treatment induced muscle-specific GLUT4 in SD rats.

\section{Discussion}

HSPs received their name based on their accidental discovery in the salivary glands of 
A

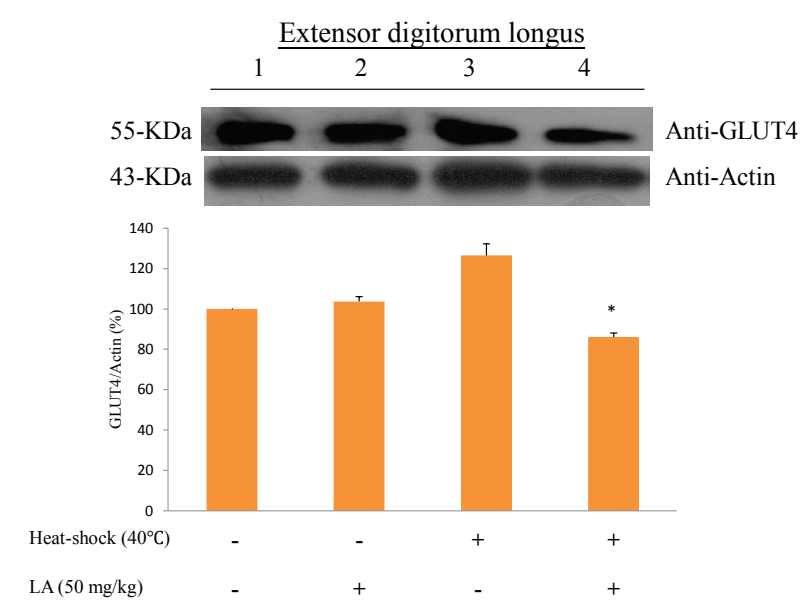

C

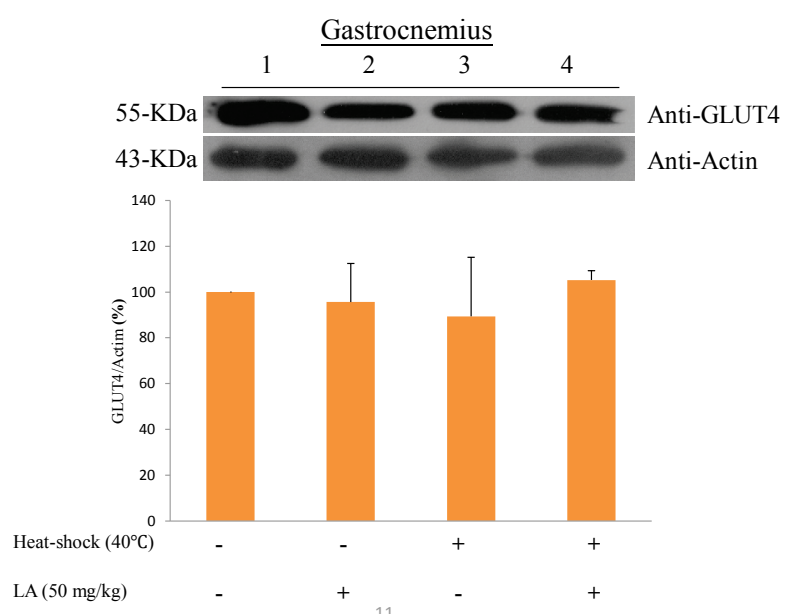

B

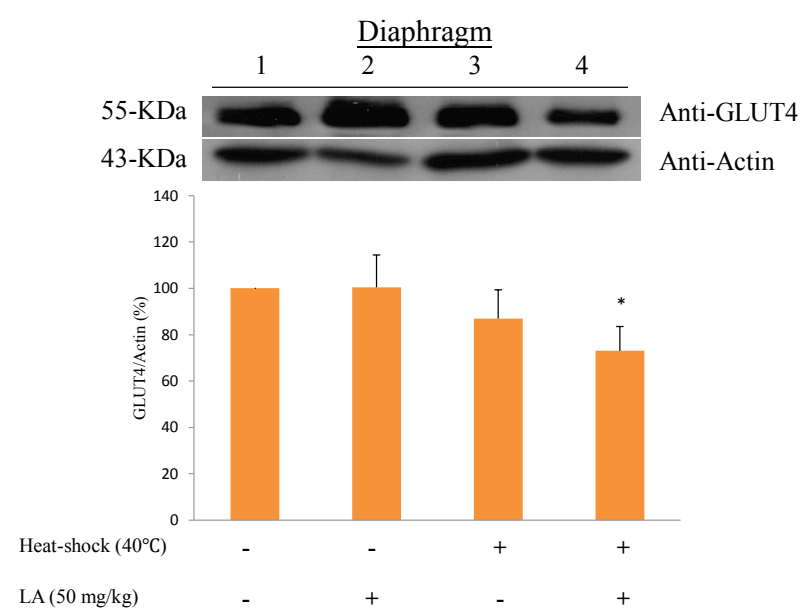

D

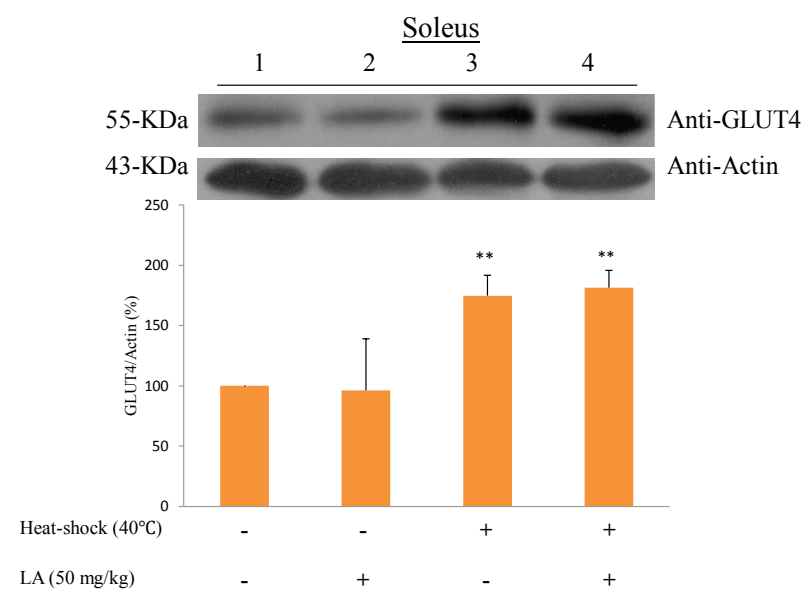

Fig. 5. Muscle-specific GLUT4 expression induced by lipoic acid (LA) and heat shock. (A), (B), (C), and (D) correspond to $15 \mu \mathrm{g}$ of protein extracts prepared from extensor digitorum longus, diaphragm, gastrocnemius, and soleus muscles, respectively. Lane 1 corresponds to the protein extract of muscles from the control group $(n=3)$. Lane 2 corresponds to the protein extract of muscles from rats injected with lipoic acid alone $(n=4)$. Lane 3 corresponds to the protein extract of muscles from rats treated with heat-shock alone $(n=4)$. Lane 4 corresponds to the protein extract of muscles from rats treated with both lipoic acid and heat-shock $(n=4)$. Data are presented as group mean \pm SEM of 3 measurements for each rat. $* P<0.05, * * P<0.01$

Drosophila busckii following transient heat stress $\left(5^{\circ} \mathrm{C}\right.$ above normal temperature) (Ritossa 1962). Exposure to heat is a traditional method frequently used to induce the expression of HSPs. Although HSP70 plays a critical role as a chaperone molecule in cells, diminished expression of HSP72 was detected in the skeletal muscles of patients with Type 2 diabetes (Bruce et al. 2003, Kurucz et al. 2002), suggesting that HSPs are key mediators of insulin sensitivity in skeletal muscles (Geiger and Gupte 2011). Therefore, identifying potential inducers of HSPs in skeletal muscles is crucial. In this study, our in vitro experiments revealed that lipoic acid, heat-shock, and combined lipoic acid and heat-shock treatments increased HSP70 (Fig. 1), indicating that treatment with lipoic acid alone for $24 \mathrm{~h}$ induced significantly greater HSP70 than did treatment with lipoic acid alone for $3 \mathrm{~h}$. These results suggested that lipoic acid increases HSP70 in response to heat or lipoic acid treatment alone. However, lipoic acid and heat-shock treatments did not increase GLUT4 in $\mathrm{C}_{2} \mathrm{C}_{12}$ myotubes (Fig. 2). To confirm the roles of HSP70 and GLUT4 in different skeletal muscles, an animal model was designed and 4 different skeletal muscles were obtained in this study.

Wounds heal poorly in animals with long-term hyperglycemia, and our in vitro migration/wounding assay results indicated that treatment with lipoic acid for $3 \mathrm{~h}$ increased wound closure by approximately $50 \%$, which showing the wound-healing ability of lipoic acid 
(Fig. 3). Moreover, treatment with lipoic acid for $24 \mathrm{~h}$ reduced wound closure approximately $22 \%$ compared with that in the control group, suggesting that lipoic acid might be toxic in long-term treatment. A previous study suggested that administering a high chronic dose (5 to $10 \mathrm{~g}$ per day in humans) increases plasma lipid hydroperoxide levels (Cakatay and Kayali 2005). Although lipoic acid has been used as a therapy for diabetic neuropathy and retinopathy in Germany for over 50 years, the use of lipoic acid as a nutriceutical supplement should be considered carefully in the future.

As expected, heat-shock increased the level of HSP70 in all 4 different skeletal muscles $(P<0.05$ at extensor digitorum longus, diaphragm and gastrocnemius; $P<0.01$ at soleus; Fig. 4A-D), indicating that the induction of HSP70 by heat-shock was not muscle type specific. However, lipoic acid failed to induce a significant increase in HSP70 in all 4 different skeletal muscles (Fig. 4A-D). The administration of lipoic acid injection for only 21 days might be a major factor; a longer period of lipoic acid treatment was suggested in our further study. Khamaisi et al. (1997) demonstrated that lipoic acid increases muscle GLUT4 in streptozotocin-diabetic rats. Our in vivo studies indicated that lipoic acid did not induce GLUT4 in all 4 different skeletal muscles (Fig. 5A-D) suggesting that lipoic acid might not induce GLUT4 directly in non-diabetic rats. Moreover, heat-shock alone increased GLUT4 only in the soleus muscle $(P<0.01$; Fig. $5 \mathrm{D})$, indicating that heatshock increased the GLUT4 in a muscle-specific manner, and this process was specific to the slow-twitch muscle fibers (Type I) of the rats. Bloemberg and Quadrilatero (2012) revealed that the soleus muscle comprises $96.6 \%$ type I, $0.7 \%$ Type I/IIa, and $2.7 \%$ Type IIa muscle fibers. Henriksen et al. (1990) demonstrated that GLUT4 is more abundant in slow-twitch muscles than in fasttwitch muscles. In addition, Stuart et al. (2010) reported that exercise increases the GLUT4 in fast-twitch muscles, and Xiao et al. (2013) indicated that exercise increases the GLUT4 in both fast-twitch and slow-twitch muscles. Our results revealed that heat-shock induced GLUT4 only in the soleus of the rats. This result might be attributable to the greater abundance of GLUT4 in slow-twitch muscles than in fast-twitch muscles; however, this process should be clarified further in future studies. Furthermore, our results indicated that combined lipoic acid and heat-shock treatment reduced GLUT4 in the extensor digitorum longus $(P<0.05$; Fig. 5A $)$ and diaphragm $(P<0.05$; Fig. 5B). Studies have demonstrated that exercise increases insulin-stimulated GLUT4 translocation to the cell surface membrane without altering the total abundance of GLUT4 (Douen et al. 1990, Hansen et al. 1998). Whether the low level of GLUT4 in the extensor digitorum longus and diaphragm are related to glucose use by the muscles requires further investigation.

In conclusion, we report that heat-shock increased the slow-twitch-muscle-specific GLUT4 in SD rats.

\section{Conflict of Interest}

There is no conflict of interest.

\section{Acknowledgements}

The authors thank Prof. L. S. Chang, Institute of Biomedical Sciences, National Sun Yat-Sen University, Taiwan, for his encouragement during this study.

\section{References}

ABADI A, CRANE JD, OGBORN D, HETTINGA B, AKHTAR M, STOKL A, MACNEIL L, SAFDAR A, TARNOPOLSKY M: Supplementation with $\alpha$-lipoic acid, CoQ10, and vitamin E augments running performance and mitochondrial function in female mice. PLoS One 8: e60722, 2013.

BAST A, HAENEN GR: Interplay between lipoic acid and glutathione in the protection against microsomal lipid peroxidation. Biochim Biophys Acta 963: 558-561, 1988.

BLOEMBERG D, QUADRILATERO J: Rapid determination of myosin heavy chain expression in rat, mouse, and human skeletal muscle using multicolor immunofluorescence analysis. PloS One 7: e35273, 2012.

BRUCE CR, CAREY AL, HAWLEY JA, FEBBRAIO MA: Intramuscular heat shock protein 72 and heme oxygenase1 mRNA are reduced in patients with type 2 diabetes: evidence that insulin resistance is associated with a disturbed antioxidant defense mechanism. Diabetes 52: 2338-2345, 2003.

CAKATAY U, KAYALI R: Plasma protein oxidation in aging rats after alpha-lipoic acid administration. Biogerontology 6: 87-93, 2005. 
DOUEN AG, RAMLAL T, RASTOGI S, BILAN PJ, CARTEE GD, VRANIC M, HOLLOSZY JO, KLIP A: Exercise induces recruitment of the "insulin-responsive glucose transporter". Evidence for distinct intracellular insulinand exercise-recruitable transporter pools in skeletal muscle. J Biol Chem 265: 13427-13430, 1990.

GEIGER PC, GUPTE AA: Heat shock proteins are important mediators of skeletal muscle insulin sensitivity. Exerc Sport Sci Rev 39: 34-42, 2011.

HANSEN PA, NOLTE LA, CHEN MM, HOLLOSZY JO: Increased GLUT-4 translocation mediates enhanced insulin sensitivity of muscle glucose transport after exercise. J Appl Physiol 85: 1218-1222, 1998.

HENRIKSEN EJ, BOUREY RE, RODNICK KJ, KORANYI L, PERMUTT MA, HOLLOSZY JO. Glucose transporter protein content and glucose transport capacity in rat skeletal muscles. Am J Physiol Endocrinol Metab 259: E593-E598, 1990.

KHAMAISI M, POTASHNIK R, TIROSH A, DEMSHCHAK E, RUDICH A, TRITSCHLER H, WESSEL K, BASHAN N: Lipoic acid reduces glycemia and increases muscle GLUT4 content in streptozotocin-diabetic rats. Metabolism 46: 763-768, 1997.

KURUCZ I, MORVA A, VAAG A, ERIKSSON KF, HUANG X, GROOP L, KORANYI L: Decreased expression of heat shock protein 72 in skeletal muscle of patients with type 2 diabetes correlates with insulin resistance. Diabetes 51: 1102-1109, 2002.

LEU JG, CHEN SA, CHEN HM, WU WM, HUNG CF, YAO YD, TU CS, LIANG YJ: The effects of gold nanoparticles in wound healing with antioxidant epigallocatechin gallate and $\alpha$-lipoic acid. Nanomedicine $\mathbf{8}$ : 767-775, 2012.

LIU Y, STEINACKER JM: Changes in skeletal muscle heat shock proteins: pathological significance. Front Biosci 6 : D12-D25, 2001.

LOCKE M, NOBLE EG, ATKINSON BG: Inducible isoform of HSP70 in constitutively expressed in a muscle fiber specific pattern. Am J Physiol Cell Physiol 261: C774-C779, 1991.

PORTIER GL, BENDERS AG, OOSTERHOF A, VEERKAMP JH, VAN KUPPEVELT TH: Differentiation markers of mouse $\mathrm{C}_{2} \mathrm{C}_{12}$ and rat $\mathrm{L} 6$ myogenic cell lines and the effect of the differentiation medium. In Vitro Cell Dev Biol Anim 35: 219-227, 1999.

RITOSSA F: A new puffing pattern induced by temperature shock and DNP in Drosophila. Experientia 18: 571-573, 1962.

SCHEEPERS A, JOOST HG, SCHÜRMANN A: The glucose transporter families SGLT and GLUT: molecular basis of normal and aberrant function. JPEN J Parenter Enteral Nutr 28: 364-371, 2004.

SHAY KP, MOREAU RF, SMITH EJ, SMITH AR, HAGEN TM: Alpha-lipoic acid as a dietary supplement: molecular mechanisms and therapeutic potential. Biochim Biophys Acta 1790: 1149-1160, 2009.

STUART CA, HOWELL ME, BAKER JD, DYKES RJ, DUFFOURC MM, RAMSEY MW, STONE MH: Cycle training increased GLUT4 and activation of mammalian target of rapamycin in fast twitch muscle fibers. Med Sci Sports Exerc 42: 96-106, 2010.

TANDARA AA, MUSTOE TA: Oxygen in wound healing - more than a nutrient. World J Surg 28: 294-300, 2004.

TARRICONE E, SCAPIN C, VITADELLO M, ESPOSITO F, MARGONATO V, MILANO G, SAMAJA M, GORZA L: Cellular distribution of Hsp70 expression in rat skeletal muscles. Effects of moderate exercise training and chronic hypoxia. Cell Stress Chaperones 13: 483-495, 2008.

WAGNER AE, ERNST IM, BIRRINGER M, SANCAK O, BARELLA L, RIMBACH G: A combination of lipoic acid plus coenzyme Q10 induces PGC1 $\alpha$, a master switch of energy metabolism, improves stress response, and increases cellular glutathione levels in cultured $\mathrm{C} 2 \mathrm{C} 12$ skeletal muscle cells. Oxid Med Cell Longev 2012: 835970, 2012.

XIAO Y, SHARMA N, ARIAS EB, CASTORENA CM, CARTEE GD: A persistent increase in insulin-stimulated glucose uptake by both fast-twitch and slow-twitch skeletal muscles after a single exercise session by old rats. Age 35: 573-582, 2013.

YAMASAKI M, IWASE M, KAWANO K, SAKAKIBARA Y, SUIKO M, IKEDA M, NISHIYAMA K: $\alpha$-Lipoic acid suppresses migration and invasion via downregulation of cell surface $\beta 1$-integrin expression in bladder cancer cells. J Clin Biochem Nutr 54: 18-25, 2014.

ZHANG Y, HAN P, WU N, HE B, LU Y, LI S, LIU Y, ZHAO S, LIU L, LI Y: Amelioration of lipid abnormalities by $\alpha$-lipoic acid through antioxidative and anti-inflammatory effects. Obesity 19: 1647-1653, 2011. 